\title{
BARE NOMINALS AND OPTIMAL INFERENCE ${ }^{*}$
}

\author{
Ariel Cohen, \\ Ben-Gurion University of the Negev \\ arikc@bgu.ac.il
}

\begin{abstract}
In this paper I discuss four type of bare nominal, and note that, in some sense, all of them appear to imply stereotypicality. I consider an account in terms of Bidirectional Optimality Theory: unmarked (bare) forms give rise to unmarked (stereotypical) interpretations. However, it turns out that, while the form of bare numerals is unmarked, the interpretation sometimes is not. I suggest that the crucial notion is not unmarkedness, but optimal inference: unmarked forms give rise to interpretations that are best used for drawing inferences. I propose a revision of Bidirectional Optimality Theory to reflect this.
\end{abstract}

\section{Stereotypical Interpretations of Bare Nominals}

\subsection{Generic Bare Plurals}

What does a generic sentence like (1) mean?

(1) Ravens are black.

Clearly, this is not a universal, since the existence of the odd albino raven does not render (1) false. But what, then, does it mean? The meaning of a generic is a hotly debated topic, and I am not going to address it here. ${ }^{1}$ At a pretheoretic level, however, a reasonable approximation of the meaning of the sentence is that it makes a statement not about all ravens, but about stereotypical ravens. Since an albino raven is not stereotypical, it does not count an an exception, and does not falsify (1).

Note that I am not advocating here that the truth conditions of (1) are captured by an appeal to stereotypicality_indeed, I will argue against such a claim. ${ }^{2}$ All I am saying is that when (1) is interpreted, there is a "feeling" that stereotypicality is involved. Nothing more than this rather weak and, I believe, non-controversial claim is necessary for the purposes of this paper, as we shall see.

\subsection{Existential Bare Plurals}

Existential bare plurals are usually supposed to express nothing more than a simple existential claim. They are certainly rarely associated with notions of stereotypicality. And yet, stereotypicality does appear to play a role in their interpretation (Cohen 2005a).

Consider the following examples:

(2) a. This tractor has wheels.

\footnotetext{
* I would like to thank Manfred Krifka for helpful comments and suggestions.

${ }^{1}$ See Cohen $(1996 ; 1999)$ for my take on this question.

${ }^{2}$ Though some researchers, e.g. Geurts (1985) and Declerk (1986), argue for precisely this claim.
} 
b. This tractor has some wheels.

Suppose the tractor in question has only two wheels. Then (1a) would be odd, but (1b) would be fine. Sentence (2a), but not (2b), suggests that the tractor has four wheels, suitably arranged: two large ones in the rear, two smaller ones in front. In other words, (1a) implies that the tractor has the stereotypical arrangement of wheels.

For another example, consider the following pair, suggested by Tova Rapoport (pc):

a. John has playing cards.

b. John has Victorian playing cards.

Sentence (3a) suggests that John has the stereotypical set of cards, i.e. a full deck. Sentence (3b), on the other hand, may be felicitously uttered even if John has only a few Victorian cards; in the context of this sentence, John is most probably a collector of Victorian cards, and there is no specific set of cards that would be considered stereotypical for collecting purposes.

Even the "classic" example of an existential reading of a bare plural, namely the subject of available, may give rise to stereotypicality. Suppose we wish to send a spaceship to the moon. We contact NASA, and get the following response:

(4) Astronauts are available.

Sentence (4) says more than simply that there exist some available astronauts. Rather, it implies that there is a set of available astronauts that is stereotypical, in terms of its size, the training of its members, etc., in the context of our mission: there are, say, three astronauts, who have the respective roles of Command Module Pilot, LEM Pilot, and Mission Commander.

Note that this feeling of stereotypicality is perceived by the hearer, who may felicitously respond to it as if it were explicitly made:

(5) A: This tractor has wheels.

B: So where do you want to go with it?

(6) A: John has playing cards.

B: Great, let's start a game.

(7) A: Astronauts are available.

B: But the mission cannot go ahead, because the rocket is still malfunctioning.

B's response in (5a) relates to the implied claim that the tractor has a set of wheels suitable for the purpose of riding it; in (6b), B responds to A's implication that John has a set of playing cards suitable for playing; and in (7b), B understands A's purpose to indicate that the mission is ready (and the set of available astronauts is the appropriate stereotypical set).

\subsection{Incorporated Bare Nouns}

Carlson (2005) discusses a number of studies of incorporation in various languages. While the languages and the theoretical approaches differ substantially, all these works seem to converge on some sort of stereotypical interpretation of incorporated nouns.

Thus, for example, Borthen (2003) proposes:

A bare indefinite can occur in Norwegian if it is... selected as a complement by a predicate and together with this predicate (and possibly other selected elements) designates a conventional situation type... A conventional situation type is a property, state, or activity 
that occurs frequently or standardly in a given contextual frame (e.g. in the macro social frame) and has particular importance or relevance in this frame as a recurring property, state, or activity type (p. 160).

Similarly, Axelrod (1990) suggests that "incorporation provides the lexicalized version of a typical activity". Mithun (1984) relates the typicality implication of incorporation to frequency: "some entity, quality, or activity is recognized sufficiently often to be considered nameworthy." Mulder (1994) follows suit: "Noun incorporation in Sm'algyax occurs when a habitual activity toward an object is expressed." Similarly, de Reuse (1994) suggests that the incorporated form "refers to habitual, permanent, chronic, specialized, characteristic or unintentional activities or states, or localized events".

\subsection{Bare Goal Arguments}

Horn (1993) considers sentences with bare goal arguments:

$$
\text { My brother went to }\left\{\begin{array}{l}
\text { church } \\
\text { jail } \\
\text { school }
\end{array}\right\} \text {. }
$$

Horn notes that (8) implies that my brother went to church (jail, school) for the purpose of performing the stereotypically associated function (praying, being incarcerated, studying). In this its meaning is different from (9), which means simply that my brother changed his location to the specified location — the church (the jail, the school).

$$
\text { My brother went to a }\left\{\begin{array}{l}
\text { church } \\
\text { jail } \\
\text { school }
\end{array}\right\} \text {. }
$$

It appears, then, that four different kinds of bare nominal, which differ on their syntax, semantics, and pragmatics, share a stereotypical "flavor". Surely this cannot be mere coincidence: there must be something about bare nominals that contributes to this interpretation. How can we explain this fact?

\section{Unmarked Forms and Interpretations}

\subsection{The basic idea}

An idea that goes as far back as Atlas and Levinson (1981) and Horn (1984) can be expressed succinctly by the following well known slogan: unmarked forms receive unmarked interpretations.

The underlying notion is simple: both speaker and hearer want to minimize their effort. Unmarked (shorter) forms are easier for the speaker to produce; unmarked (stereotypical) meanings are easier for the hearer to understand. Hence, unmarked forms are preferred to marked forms, and unmarked interpretations are preferred to marked interpretations.

\subsection{Bidirectional Optimality Theory}

This notion has been formalized by Blutner $(1998 ; 2000)$ in his Bidirectional Optimality Theory. Blutner considers pairs of form and interpretation: $\langle A, \tau\rangle$ means that $\tau$ is the interpretation of $\mathrm{A}$. Blutner proposes a partial order ' $\succ$ 'on such pairs. Intuitively, $\left\langle\mathrm{A}^{\prime}, \tau\right.$ ' $\rangle \succ$ $\langle\mathrm{A}, \tau\rangle$ means that $\left\langle\mathrm{A}^{\prime}, \tau\right\rangle$ is preferred to $\langle\mathrm{A}, \tau\rangle$. A pair $\langle\mathrm{A}, \tau\rangle$ is superoptimal iff it satisfies the following two principles: 
Q principle: $\tau$ is a possible interpretation of $A$ and there is no other pair $\left\langle A^{\prime}, \tau\right\rangle$ satisfying the I principle s.t. $\left\langle\mathrm{A}^{\prime}, \tau\right\rangle \succ\langle\mathrm{A}, \tau\rangle$

I principle: $\tau$ is a possible interpretation of $A$ and there is no other pair $\langle A, \tau$ ' $\rangle$ satisfying the $\mathrm{Q}$ principle s.t. $\langle\mathrm{A}, \tau\rangle\rangle\langle\mathrm{A}, \tau\rangle$

At first sight, the combination of these two principles might appear circular, since the definition of the Q principle refers to the I principle, and the definition of the latter refers back to the former. However, this circularity is not vicious, and, in fact, the principles can predict successfully a number of phenomena.

For an example, consider the following minimal pair, from McCawley (1978):

a. Black Bart killed the sheriff.

b. Black Bart caused the sheriff to die.

McCawley notes that while (10a) implies that Black Bart killed the sheriff in a direct way (i.e. shot him), (10b) implies some indirect way of killing, e.g. sabotaging the sheriff's own gun so that it backfires.

Bidirectional Optimality Theory can account for this difference, under the plausible assumption that the stereotypical manner of killing is direct rather than indirect.

Note that the form-meaning pair <kill, direct killing> is superoptimal, since both its form (short) and its meaning (stereotypical) are preferred. But the form-meaning pair < cause to die, indirect killing $>$ is also superoptimal. This is the case, although there are pairs that are preferred to it. For example, <kill, indirect killing> is preferred (its form is shorter), but it doesn't satisfy the I-principle, because the pair <kill, direct killing $>$ is better than it. Similarly, although <cause to die, direct killing> is preferred (its meaning is stereotypical), it doesn't satisfy the Q-principle, since the pair <kill, direct killing> is better than it. Thus, we get the desired result: unmarked forms pair with unmarked meanings, and marked forms pair with marked interpretations.

It appears that Bidirectional Optimality Theory would straightforwardly account for the facts about bare nominals discussed above, provided we make two assumptions:

1. The meaning of bare nominals is unmarked (stereotypical)

2. The form of bare nominals is unmarked (shorter, easier to produce)

These assumptions appear quite reasonable; but are they tenable?

\section{Non-stereotypicality}

Let us first reconsider the claim that bare nominals receive stereotypical interpretations. We will see that this does not hold in general, in any of the four phenomena we have considered.

\subsection{Generic Bare Plurals}

It is quite easy to show that generics do not, in general, express stereotypicality. Take (11), for example:

??Mammals are placental mammals.

The stereotypical mammal is certainly a placental mammal. Hence, if generics expressed statements about stereotypes, (11) ought to be unproblematically true; but the fact is that it is quite bad. 
It might be argued that the problem with is simply the fact the same word, mammals, occurs in both subject and predicate. Perhaps this is what makes the sentence awkward. To see that this is not the case, consider the following examples:
a. ??Primary school teachers are female.
b. ??People are over three years old.

Although the stereotypical primary school teacher is female, (12a) is bad, and although the stereotypical person is an adult, (12b) is very odd.

Elsewhere (Cohen 1996; 1999; 2004) I account for such facts by proposing that generics carry a homogeneity presupposition. The generic $\operatorname{gen}(\psi, \varphi)$ presupposes that its domain, $\psi$, is homogeneous, in the following sense: for any psychologically salient criterion by which $\psi$ may be partitioned into subsets, the conditional probability of $\varphi$ ought to be roughly the same given every such subset of $\psi$. That is to say, the domain of a generic may not have "chunks" where there are significantly more $\varphi s$ or significantly fewer $\varphi s$ than there are in the rest of $\psi$.

Homogeneity corresponds rather well to the pretheoretical notion of what a generic sentence means. For example, suppose a friend is coming to Israel for a visit, and is worried about whether she will be able to manage, speaking only English. We reassure her by saying

\section{(13) Israelis speak English.}

Observe that (13) means more than simply that if you meet an Israeli, he or she is likely to speak English; in addition, the sentence requires that, wherever you go in Israel, whichever group of Israeli society you associate with, a member of this community will be likely to speak English. Indeed, suppose the friend spent all her visit in a town where nobody spoke English, or with members of some group of Israeli society where English was rarely spoken. In such a case, she would be justified in accusing us of misleading her.

Homogeneity can explain the oddness of examples (11-12) above. Partition according to biological group violates homogeneity: one subset (the placental mammals) satisfies the property, another (marsupials) does not. Hence, (11) is bad.

Sentence is (12a) is odd because partition according to sex violates homogeneity: one subset (the females) satisfies the property, another (the males) does not. And (12b) is bad because partition according to age violates homogeneity: some subsets (adults) satisfy the predicated property, others (babies and toddlers) do not.

Why do generics have this requirement? In Cohen (1996) I suggest that homogeneity is useful for inference. If the domain is homogeneous, we are safe from local minima. That is to say, we will not find ourselves in a situation where, because of bad luck, we happen to find ourselves dealing with a subset of the domain where all our inferences are wrong.

For example, consider (1) again, repeated below:

Ravens are black.

This sentence is acceptable and true, despite the existence of albino ravens. Why? The reason is that albino ravens are homogeneously distributed throughout the raven community-there are no colonies of albino ravens. Hence, if, whenever we encounter a raven, we infer that it is black, this inference will be justified. It might not always prove correct-sometimes we will encounter the odd albino raven - but it will not be repeatedly wrong.

Hence, I suggest that the crucial notion which prefers an interpretation of a bare nominal is not whether the interpretation is stereotypical as such, but whether it provides information that is useful for inference. Thus, a generic implies that inferences about its domain are generally reliable. Of course, one of the ways to aid inference is stereotypicality; indeed, this is arguably why we have stereotypes. But it is not the only way: another one is homogeneity. 


\subsection{Existential Bare Plurals}

We have seen above that existential bare plurals often imply stereotypicality. Indeed, stereotypicality can aid inference. For example, the hearer of (2a), repeated below, can draw inferences about the tractor (e.g. that it can run).

(15) This tractor has wheels.

However, existential bare plurals are not always interpreted stereotypically. Consider the following sentence:

(16) In this forest, trees are dying.

The stereotypical, indeed the common situation where trees are dying is where the trees are concentrated in some area, the location that was first infected. However, in such a case, where only a single grove out of the forest is dying, (16) would be quite odd. Rather, (16) seems to indicate that the dying trees are homogeneously distributed throughout the forest. ${ }^{3}$

As in the case of generics, so in the case of existential bare plurals, homogeneity serves as an aid to inference. The hearer of (16a) can draw inferences about the forest (e.g. that it is sick), which would not be possible if only a single grove were infected.

For further examples of existential bare plurals that express homogeneity, consider the following sentences, after Greenberg (1994):

(17) a. (Although it is winter now, in our country...) lakes are dry.

b. (Wellington's army has won a great victory today, but...) soldiers are tired.

c. (It is New Year's Eve, and...) restaurants are full.

Note that if only lakes located in a specific geographical region, or only salt-water lakes were dry, (17a) would be odd; rather, the sentence implies that throughout the country, lakes are dry. Similarly, (17b) would be bad if only the young soldiers, or only the soldiers in a specific platoon were tired; its acceptability requires that soldiers from a variety of ages, units, etc. be tired. As for $(17 \mathrm{c})$, if only Italian restaurants, or only restaurants on a specific street were full, it would be odd; (17c) implies that various types of restaurant, throughout town, are full.

\subsection{Incorporated Bare Nouns}

We have seen that incorporation often implies stereotypicality. What is the role of stereotypicality? Asudeh and Mikkelsen (2000), discussing syntactic noun incorporation in Danish, propose that it is subject to the following constraint:

the resulting predicate must denote an action that is 'institutionalized'

(Rischel, 1983). In other words, the denotation of the incorporated verb phrase must be an action or event which is conventionally associated with a certain structure or set of activities (pp. 5-6)

Asudeh and Mikkelsen present the following pair (phonological phrasing is indicated by square brackets):

$$
\begin{aligned}
& \text { a. Min nabo [p købte hus] sidste år } \\
& \text { My neighbor bought house last year }
\end{aligned}
$$

\footnotetext{
${ }^{3}$ Or, at least, that the disease is spreading, and that the dying tress will be homogeneously distributed in the near future.
} 
'My neighbour did house-buying last year.'

b. \#Min nabo [p købte blyant] igår

My neighbor bought pencil yesterday.

Why is (18a) fine, while (18b) is bad? Borthen (2003) explains: "there are presumably more conventionally associated activities connected to buying a house than buying a pen, which is in accordance with the fact that in Danish, the action of buying a house can be expressed with a sentence that contains a bare singular referring to the house, whereas the action of buying a pen cannot" (p. 94).

Incorporated mominals, however, do not always denote a stereotypical activity. Just like with generic and existential bare plurals, incorporated nominals sometimes indicate homogeneity.

In his discussion of verbal incorporation in Chukchi, Dunn (1999) notes that:

the stem qora-nm-at - 'slaughter reindeer'... refers to something which, in Chukchi culture, is a unitary activity and is exceptionally nameworthy as a focus of ritual activity and the high point of a day... this incorporation... only refers to reindeer-killing in its traditional Chukchi cultural context, i.e. killing of a domestic meat reindeer with a knife in the prescribed manner with all attendant ritual" (p. 223, my emphasis).

This traditional manner of killing reindeer is unitary, i.e. presumably homogeneous, and gives rise to a number of inferences (e.g. about the fact that the animal is domestic, that the killing is done with a knife, etc.), which anyone familiar with the Chukchi culture may draw.

\subsection{Goal Arguments}

We have seen that bare goal arguments imply stereotypicality. This cannot, however, be the only factor. If it were, we would expect sentences like (19) to be fine, and to imply that my brother went to the beach to perform the stereotypically associated activity (bathing).

*My brother went to beach

The fact is, however, that (19) is bad. Why, then, is (8), repeated below, good?

$$
\text { My brother went to }\left\{\begin{array}{l}
\text { church } \\
\text { jail } \\
\text { school }
\end{array}\right\} \text {. }
$$

The explanation I propose is that churchgoers, prison inmates, and school children are fairly homogeneous groups, and many inferences can be made about them. If we learn that the speaker's brother belongs to one of these groups, there is a fair amount of information we can infer about him. In contrast, this is not the case for beachgoers. What inference can we draw about the speaker's brother on the basis of his going to the beach?

\subsection{Dutch Predicate Nominals}

Perhaps the clearest case of bare nominals that give rise to an implication of homogeneity is provided by Dutch predicate nominals, studied by de Swart, Winter, and Zwarts (2004). For example, (21a), which uses a bare nominal, implies that being a manager is Henriëtte's job. In contrast, (21b) merely says that Henriëtte has administrative duties.

(21) a. Henriëtte is manager.

'Henriëtte is manager' 
b. Henriëtte is een manager.

'Henriëtte is a manager'

The class of managers is a much more homogeneous group that than of people with administrative duties. Hence, from (21a), but not from (21b), we can infer all sorts of facts about Henriëtte; this is why (21a) uses a bare nominal, while (21b) does not.

To give another example, (22a) implies that Marie's husband is literally a dictator, while (22b) merely expresses the statement that he behaves in a dictatorial fashion.

(22) a. Maries echtgenoot is dictator.

'Marie's spouse is dictator.'

b. Maries echtgenoot is een dictator.

'Marie's spouse is a dictator.'

Again, we can draw many more inferences about Marie's husband if we know that he belongs to the homogeneous group of country leaders who are dictators; we can tell much less about him just on the basis of his dictatorial behavior.

One more example is provided by the sentences in (23).

(23) a. hij is visser

'He is a fisherman'

b. hij is een visser

'He is fishing'

While (23a) says that he belongs to the rather homogeneous group of people whose profession is fishing, (23b) merely says that he is fishing at the time of utterance. Clearly, we can infer much more from the former than from the latter interpretation.

The phenomenon of class qualifiers provides evidence that what is at issue here really is homogeneity. These are qualifiers that are used when the predicate is taken to indicate that the argument belongs to a certain class. Significantly, such qualifiers are possible with the bare form of the predicate nominal, but not with the explicit indefinite form:

a. Jan is $\left\{\begin{array}{l}\text { advocaat van beroep } \\ \text { Belg van nationaliteit } \\ \text { christen van religie }\end{array}\right\}$.

b. * Jan is een $\left\{\begin{array}{l}\text { advocaat van beroep } \\ \text { Belg van nationaliteit } \\ \text { christen van religie }\end{array}\right\}$.

Jan is $\left\{\begin{array}{l}\text { a lawyer by profession } \\ \text { of Belgian nationality } \\ \text { of the Christian faith }\end{array}\right\}$. 
Thus, the predicate nominal indicates that Jan belongs to the group of professional lawyers, Belgian nationals, or religious Christians; all these groups are perceived (rightly or wrongly) to allow the hearer to draw some inferences about Jan.

Compare the above to Borthen's characterization of the type of cases that allow bare singular objects in Norwegian. She notes that the bare singular is fine in sentences like those in (25), but bad in sentence such as those in (26).

(25) a. Hun er kontorist.

she is clerk

'She is a clerk.'

b. Hun er bellonamedlem.

she is Bellona-member

'She is a Bellona member.'

(26) a.??Per er liten gutt.

Per is little boy

'Per is a little boy.'

b. */??Han er kjernekar.

he is splendid-chap

'He is a splendid chap.'

Borthen's explanation of these facts notes that the properties predicates in (25) denote homogeneous groups, whereas those in (26) do not. In her own words:

One particularly prominent and frequently relevant contextual frame for humancommunication, is the macro social frame. For Norwegian, this means the Norwegian society. In this frame, human beings are categorized relative to certain properties. Job, political affiliation, and religion, for instance, are all important properties of individuals because the society or community is organized in terms of these properties; rules make reference to them, money is being distributed according to them, and people are listed and kept track of according to them. On the other hand, being or not being-let's say—a splendid chap, a little boy, or a boring woman, for instance, might be of importance to these individuals' friends, but in the macro social frame these properties are irrelevant; no rules refer to them, no money is being distributed according to them, and presumably no lists of splendid chaps, little boys, or boring women exist anywhere in the system (p. 126).

\subsection{Inference and Preference}

It should be emphasized that homogeneity and stereotypicality are quite distinct concepts. While it might be argued that stereotypicality is the unmarked interpretation, no such argument can be made for homogeneity. Indeed, there is no reason to assume a-priori that the domain of inference is homogeneous-in most cases, this will not be so. Hence, the implication of homogeneity is actually quite informative, and is therefore not simply the unmarked reading. 
I propose, then, that the crucial notion is not unmarkedness, but aid to inference. We prefer an interpretation not on the basis of how easy it is to assume it, but on the basis of its potential to support inference.

Using the notation of Bidirectional Optimality Theory, this means that

$\langle\mathrm{A}, \tau\rangle \succ\langle\mathrm{A}, \tau$ ' $\rangle$ if $\tau$ aids inference, by either:

1. being more stereotypical, or

2. by implying that the domain of inference is homogeneous.

At this point, I ought to clarify what I am not saying. It is not my claim that every stereotypical or homogeneous statement is expressed using bare nominals. Clearly, there are other ways to express these notions. However, I am claiming the converse: namely, that every use of bare nominals implies that inferences are facilitated, either because the interpretation is stereotypical, or because the domain of inference is homogeneous.

\section{Is the Form Unmarked?}

We have seen that the preferred interpretation is not necessarily the unmarked one, as claimed by Bidirectional Optimality Theory, but the one that best supports inferences. What about the form? Is the preferred form the unmarked one? Or does an alternative factor apply here as well?

\subsection{The Data}

Bare nominals are, in a sense, underspecified: they leave out the determiner. There is some reason to believe that underspecified interpretations are preferred (Krifka 2002). But what about underspecified forms?

Obviously, a bare nominal is shorter than a full DP. It is therefore arguably easy to produce. We could therefore say that bare nominals are preferred, because it takes less effort to produce them.

There is, however, a problem with this idea: what is expressed by a bare nominal in one language, is expressed by a definite determiner in another. We can see this in all four forms of bare nominal we have considered.

\section{(i) Generic plurals}

While generic plurals are bare in English, they are explicitly definite in Romance. Thus, the translation of (1) into Spanish is:

(27) Los cuervos son negros.

'The ravens are black'.

\section{(ii) Existential plurals}

In Romance, existential plurals that imply stereotypicality/homogeneity are not bare, but rather definite. Thus, the translation of (2a) into Italian is:

(28) Questo trattore ha le ruote (G. Longobardi, pc)

'This tractor has the wheels'.

\section{(iii) Incorporated nominals}

Carlson (2005) notes that incorporated nominals are often translated into English as definites:

a-urapá-pirár (Tupinambá-Mithun 1984) 
I-bow-open

'I draw my bow'

(30)

Nej-Ek 'ElE-lgE-g'i (Chukchi-Polinsky 1990)

hill-LOC snow-melt-3SG.S

'On the hill, the snow melted.'

\section{(iv) Goal arguments}

In Spanish, instead of bare nominal goal arguments, we have definites. Thus, the translation of (8) is:

$$
\begin{gathered}
\text { Mi hermano fue a la }\left\{\begin{array}{l}
\text { iglesia } \\
\text { carcel } \\
\text { escuela }
\end{array}\right\} . \\
\text { 'My brother went to the jail }
\end{gathered}
$$

\subsection{Definites as a Last Resort}

It appears that we can draw the following generalization: languages that can use a bare nominal in the constructions we have discussed, do so. Languages that cannot, use a definite, rather than an indefinite, instead. While it makes sense to assume that a bare nominal is easier to produce than an overt indefinite, could we also argue that a definite is easier to produce than an indefinite?

I would like to offer a speculative affirmative answer to this question. Definites are obviously more prominent than indefinites on the definiteness hierarchy (Comrie 1989). This hierarchy has considerable explanatory power, and has been correlated with other prominence hierarchies. For example, subjects are more prominent than objects, and animate individuals are more prominent than inanimate ones. It turns out that subjects are more likely to be definite, while objects are more likely to be indefinite. This, indeed, has been seen as an explanation for the phenomenon of Differential Object Marking: "the most natural kind of transitive construction is one where the [subject] is high in animacy and definiteness, and the [object] is lower in animacy and definiteness; and any deviation from this pattern leads to a more marked construction" (Comrie 1989, p. 128). Hence, some languages have a special way of marking definite objects (sometimes in addition to specific indefinite objects), contrasting them with indefinite ones.

If definites are higher on the prominence scale than indefinites, they may be more easily accessible, hence easier to produce. Let us see how we can use this principle to account for the distribution of definites in the cases discussed here:

\section{(i) Generic plurals}

In Romance, BPs cannot denote kinds (Longobardi 2001). ${ }^{4}$ Elsewhere (Cohen 1996; 2005b), I argue that all generic readings, whether characterizing generics or direct kind predication, require reference to kinds. If this is granted, then Romance BPs cannot get generic readings. Consequently, a different construction is required to express genericity. Since definites are higher on the prominence scale than indefinites, they are chosen.

\footnotetext{
${ }^{4}$ Chierchia (1995) claims that this is not the case, but his arguments are rather weak; see Cohen (2005b) for discussion.
} 


\section{(ii) Existential plurals}

Although existential bare plurals are not topical (Cohen and Erteschik-Shir 2002), when they express stereotypiality or homogeneity, they are typically deaccented. Indeed, when stressed, they can only be read contrastively:
a. THIS tractor has wheels.
b. This tractor HAS wheels.
c. ?This tractor has WHEELS.

Thus, it is easy to accommodate a context where (32a) is acceptable (e.g. when comparing this tractor with some other, wheeless tractor). It is also easy to accommodate such a context for (32b) (e.g. when it is uttered as a response to someone who claimed the absence of wheels on the tractor). In contrast, (32c) is somewhat odd, and it is hard to think of a context where it would be acceptable-perhaps when used to correct another speaker's utterance that the tractor has, say, legs.

It is well known that Romance languages disprefer pragmatic deaccenting; hence, producing a bare nominal would not be so easy after all, since it would carry the cost of deaccenting. Consequently, definite plurals are actually easier. Since they are also easier than indefinites, being higher on the prominence scale, they are selected for production.

\section{(iii) Incorporated nominals}

English does not allow verbal incorporation. The most natural translation of an incorporated noun may be as a bare singular; however, English usually does not allow bare singulars in argument positions either. Hence, because of the prominence hierarchy, the best remaining option is to use definite singulars instead.

\section{(iv) Goal arguments}

Since Romance does not allow bare singulars in argument position, and since definites are more prominent than indefinites, a definite singular is produced instead.

\section{Conclusion}

We can conclude that the preferred forms are those that are easier to produce, and the preferred interpretations are those that aid inference. Applying the machinery of Bidirectional Optimality Theory, this results in the desired superoptimal form-interpretation pairs.

For example, with respect to the sentences in (2), the superoptimal pairs are:

1 <wheels, stereotypical interpretation>

2. <some wheels, non-stereotypical interpretation>

An interpretation can aid inference, hence be preferred, by either providing stereotypical information, or by indicating that the domain is homogeneous.

A form is preferred if it is easier to produce: this means that it is the shortest expression that is consistent with the constraints of the specific language spoken.

Plugging these constraints into Bidirectional Optimality Theory, it follows that bare nominals receive interpretations that are optimal for inference.

\section{References}

Asudeh, A.and L.H. Mikkelsen.(2000) .'Incorporation in Danish: Implications for interfaces.' In Cann,R.,C.Grover,and P.Miller (eds.): A Collection of Papers on Head-driven Phrase Structure Grammar. Stanford University. 
Atlas, J. and S.C. Levinson (1981) 'It-clefts, informativeness, and logical form: Radical pragmatics (revised standard version)', in P. Cole (ed) Radical Pragmatics. New York: Academic Press, 1-61.

Axelrod, M. (1990). 'Incorporation in Koyukon Athapaskan'. International Journal of American Linguistics 56(2), 179-195.

Blutner, R. (1998) 'Lexical pragmatics.’ Journal of Semantics 15(2): 115-162.

Blutner, R. (2000): 'Some aspects of optimality in natural language interpretation'. Journal of Semantics 17:189-216.

Borthen, K. (2003). Norwegian Bare Singulars. Doctoral Dissertation, Norwegian University of Science and Technology, Trondheim.

Carlson, G. (2005) 'The meaningful bounds of incorporation.' Talk presented at the Conference Indefinites and Weak Quantifiers, Brussels.

Chierchia. G (1995) 'Individual predicates as inherent generics.' In: G. N. Carlson and F. J. Pelletier (eds.): The generic book, 176-223. Chicago: University of Chicago Press

Cohen (1996) Think Generic! The Meaning and Use of Generic Sentences. Doctoral Dissertation, Carnegie-Mellon University. Published 1999, CSLI, Stanford.

Cohen, A. (1999) 'Generics, frequency adverbs, and probability. Linguistics and Philosophy 22: 221-253.

Cohen, A. (2004) 'Generics and mental representation'. Linguistics and Philosophy, 27(5), 529-556.

Cohen (2005a) 'More than bare existence: an implicature of existential bare plurals'. Journal of Semantics. 22: 389 - 400

Cohen, A. (2005b) 'The meaning of bare plurals: evidence from Italian.' Talk presented at the Conference Indefinites and Weak Quantifiers, Brussels.

Cohen, A.and N. Erteschik-Shir (2002). 'Topic, focus, and the interpretation of bare plurals.' Natural Language Semantics 6:339-405.

Comrie, B. (1989) Language Universals and Linguistic Typology, 2nd ed., University of Chicago Press, Chicago.

Declerk, R. (1986) `The manifold interpretations of generic sentences’ Lingua 68:149-188.

Dunn, M. (1999). A Grammar of Chukchi. Ph.D. dissertation, Australian National University, Canberra.

Greenberg, Yael: 1994, Hebrew nominal sentences and the stage/individual level distinction., Master's thesis, Bar-Ilan University.

Geurts B., (1985): 'Generics.' Journal of Semantics 4, 247-55. 
Horn, L. R.: (1984), 'Toward a new taxonomy for pragmatic inference: Q-based and R-based implicature', in D. Schiffrin (ed.), Meaning, Form, and Use in Context: Linguistic Applications, pp. 11-42. Georgetown University Press, Washington.

Horn, L. R.: (1993), 'Economy and redundancy in a dualistic model of natural language', in S. Shore and M. Vilkuna (eds.) SKY 1993: 1993 Yearbook of the Linguistic Association of Finland, pp. 33-72. The Linguistic Association of Finland, Turku.

Krifka, M. (2002) 'Be brief and vague! And how Bidirectional Optimality Theory allows for verbosity and precision.' In Sounds and systems: studies in the structure and change. A Festschrift for Theo Vennemann, eds. David Restle and Dietmar Zaefferer, 439-458. Berlin / New York: Mouton de Gruyter.

Longobardi, G. (2001) 'How comparative is semantics? A unified parametric theory of bare nouns and proper names' Natural Language Semantics 9, 335-369.

McCawley, J.D. (1978). 'Conversational implicature and the lexicon'. In: Syntax and Semantics 9: Pragmatics (P. Cole, ed.), pp. 245-259. Academic Press, New York.

Mithun, M. (1984). `The evolution of noun incorporation'. Language 62, 847-94.

Mulder, J. G. (1994). Ergativity in Coast Tsimshian (Smíalgyax). Universiry of California Press: Berkeley.

Polinsky, M. (1990). 'Subject incorporation: evidence from Chukchee.' In: Dziwirek et al. (eds.): Grammatical Relations: A Cross-Theoretical Perspective. Stanford: CSLI, 349364.

de Reuse, W. (1994) 'Noun incorporation in Dakota (Siouan).' International Journal of American Linguistics 60(3), 199-260.

Rischel, J. (1983) 'On unit accentuation in Danish - and the distinction between deep and surface phonology.' Folia Linguistica 17:51-97.

de Swart, H., Y. Winter and J. Zwarts (2004) 'The interpretation of bare predicate nominals in Dutch'. Unpublished ms. 